\title{
Reviewing the Development of Self-Concept: Implications for an Enhanced Model
}

\author{
Delany A. Collyer ${ }^{1}$, Janet J. Boseovski ${ }^{1} \&$ Stuart Marcovitch ${ }^{1}$ \\ ${ }^{1}$ Department of Psychology, University of North Carolina at Greensboro, Greensboro, NC, USA \\ Correspondence: Stuart Marcovitch, Department of Psychology, University of North Carolina at Greensboro, \\ Greensboro, NC, 27402, USA. Tel: 1-336-256-0020. E-mail: s_marcov@uncg.edu
}

Received: February 24, 2018 Accepted: April 16, 2018 Online Published: April 28, 2018

doi:10.5539/jedp.v8n1p171 URL: http://doi.org/10.5539/jedp.v8n1p171

\begin{abstract}
According to the multiple self-aspects framework, self-concept structure is highly influenced by overlap between self-aspects, and affective spillover may occur when affective reactions to feedback in one domain affect the highly overlapping self-aspects. We review the literature on this framework focusing on developmental implications, and present evidence that trait and emotion information is organized into a self-concept structure at an early age. Further, we propose ways in which examining self-concept contents and structure may inform our understanding of children's motivation and emotion regulation, the organization of self-aspects across development, and the refinement of models of the emergence and development of self-views.
\end{abstract}

Keywords: self concept; overlapping self-aspects; emotion regulation

\section{Introduction}

Emani, an aspiring scientist, comes home from elementary school distraught about feedback on her recent science projects. The negative feedback has impacted her views of herself more broadly, convincing her that she is a failure at school. Her motivation to continue exerting effort into her science and schoolwork is drained. Although her views about herself at school cannot be remediated right away, her father helps to repair her feelings by reminding her that she is a wonderful sister and daughter. Why does the feedback that Emani received about her projects generalize to her views of herself in all areas of school? Why is her father's consolation effective for uplifting her mood, even though it is unrelated to the source of the issue? How will Emani's views of herself as a scientist, student, sister, and daughter develop across time, independently and in relation to each other? These questions (and several others) can be addressed by considering the impact of self-concept structure on children's cognitions and affect about the self. In this article, we propose that a thorough investigation of self-concept that allows for the inclusion and direct examination of self-concept structure will lead to a richer understanding of children's experience of the self and development of the self across time.

Self-concept refers to overall views of the self, including "[trait] content, attitudes, or evaluative judgments" (Oyserman, Elmore, \& Smith, 2012, p. 72). According to the multiple self-aspects framework, self-concept is the overarching knowledge structure in which ideas about the self are grouped under given roles or domains (e.g., "me as a sibling", "me at school"), forming meaningfully distinguishable categories known as "self-aspects" (Harter, 1983; McConnell, 2011; Shavelson, Hubner, \& Stanton, 1976). Self-aspects may be drawn from several sources, including social categories (e.g., gender, race), social relationships (e.g., daughter/son, sibling, friend), or identities related to activity domains (e.g., sports team member, artist, writer).

The contents of self-aspects can include autobiographical memories (Nelson \& Fivush, 2004), evaluations (i.e., overall positive or negative views of worth or ability; Harter, 1985; Marsh, Craven, \& Debus, 1991), specific emotions, and psychological traits. For practicality of measurement, researchers often focus on a more limited scope of self-concept contents. Children's general feelings about their self-aspects have already been widely considered in research; because of this, we focus on extending our understanding of self-concept structure by including the psychological trait and emotion labels accessible to young children. A preliminary basis for psychological self-concept occurs early in development (Brown, Mangelsdorf, Agathen, \& Ho, 2008; Eder, 1990); understanding this early development better may open avenues for encouraging optimal patterns of self-concept for maintaining motivation, emotion regulation, and healthy trait-based self-concept across development. 
According to the multiple self-aspects framework, the key influence of self-concept structure is derived from overlap between self-aspects. Highly overlapping self-aspects may occur when, for example, children's views of themselves in their sibling and school roles are highly similar (e.g., children believe they are talkative and fair in both roles). If, however, their views of themselves in these roles are pretty distinctive (e.g., children believe they are talkative and domineering in their school role but kind and fair in their sibling role), this demonstrates low overlap between self-aspects (McConnell, 2011).

The level of overlap may influence affective reactions to feedback. The affective spillover hypothesis states that affective reactions to feedback in one domain are likely to "spill over" to other, highly overlapping self-aspects (Linville, 1987). Emani's generalization of the feedback about her scientist self-aspect to her student self-aspect indicates strong cognitive overlap between these two roles; in other words, Emani has similar self-concept content in her scientist and student self-aspects, creating more "spillover" of feedback from one role to the other (Linville, 1987). In contrast, Emani's father drew her attention to a self-aspect less related to her scientist or student roles, and thus less affected by the negative feedback. Although this does not repair her negative views as a scientist, it helps her focus on her positive self-aspects unaffected by spillover. People differ in their self-concept structure such that some people are more susceptible than others to high levels of spillover, whereas others have more compartmentalized self-aspects to draw upon for effective self-affirmation and perspective-taking (Critcher \& Dunning, 2014; Renaud \& McConnell, 2002). This example demonstrates the impact of self-concept structure on broader self-concept, motivation, and emotion regulation. Knowledge about the development of self-concept structure may allow for predictions about the future pursuits and self-views of children like Emani.

Below, we conducted a systematized review of the literature on self-concept as a knowledge structure in children. We searched PsycINFO using appropriate key terms, as well as examined the reference sections of the papers and looked up additional work from authors prominent in the field. Although we do not cover these developmental theories in depth, we briefly present the connections that exist between current theories and future directions opened up by the further examination of self-concept development. We present evidence that trait and emotion information is organized into a self-concept structure at an early age, and propose ways in which examining self-concept contents and structure may inform our understanding of children's motivation and emotion regulation, the organization of self-aspects across development, and the refinement of models to understand the emergence and development of self-views. We assert that recognizing and measuring a more complete formulation of self-concept contents and structure will expand our conceptual understanding of both the emergence and impact of self-concept considerably.

\section{Early Self-Concept Structure}

To substantiate our claim that self-concept structure matters in development in ways beyond those that have hitherto been considered, we must first establish that children have distinctive self-aspects early in development. There is direct evidence that children differentiate their self-concept for academic and social self-aspects by assigning different evaluations of their worth and ability (Harter, 1985; Marsh et al., 1991) to these self-aspects. However, children may assign different psychological or emotional traits to different self-aspects. Below we present evidence that children associate traits with different social categories/identities, social relationships, and activity domains, and that they use these roles or domains as self-aspects.

According to essentialism, preschool children believe in "kinds" of people with inherent, defining traits (Gelman, 2003). Social categories are one way that children mentally capture these "kinds" (Bigler \& Liben, 2007). Children expect social categories to be predictive of how others behave (Diesendruck \& haLevi, 2006; Murphy \& Medin, 1985), and preschoolers consider these categories more informative than past behaviors or preferences in determining others' future actions (Kalish \& Lawson, 2008). This predictive power may come from the assignment of stable traits to certain groups (Liu, Gelman, \& Wellman, 2007). Young children associate stereotypical traits with social categories, including gender (Reis \& Wright, 1982), race (Pauker, Ambady, \& Apfelbaum, 2010), and age (Bennett \& Sani, 2008). Around 5 years old, children also begin to use social relationships as predictive social categories (Spokes \& Spelke, 2016); for example, 5-year-olds expect family members (but not non-family members) to share similar psychological traits (Sani \& Bennett, 2009).

Importantly, 5-year-olds have been shown to incorporate social categories (such as age and racial groups) and social relationships (such as family roles) into the self (Bigler \& Liben, 2007; Cvencek, Greenwald, \& Meltzoff, 2016; Sani \& Bennett, 2009). When the self is identified with roles or groups, the personally and socially imbued associations with those groups consequently become part of the self-concept structure and impact views of the self (Greenwald et al., 2002); for example, even preschoolers experience gender-related stereotype threat (Ambady, Shih, Kim, \& Pittinsky, 2001). 
Finally, children may also assign traits to different activity domains. As mentioned previously, children differentiate their worth and ability self-concept for different activity domains (such as "Reading" and "Math" selves; Marsh et al., 1991). Although there is less direct evidence of trait associations with activity domains, children do respond to activity domain labels in a special way. For instance, 3 - to 6-year-olds demonstrate stronger corresponding behavioral responses to role-based labels, such as "helper", than to merely action-based language, such as "helping" (Bryan, Master, \& Walton, 2014). Children also consider labeled roles (e.g., "carrot-eater") more concrete and meaningful than behavioral descriptions (e.g., "eats carrots"; Gelman \& Heyman, 1999). These responses suggest that children may be predisposed to attend to activity-based roles. As children create schemas for these roles, they may include traits as a way of summarizing behavioral regularities (Liu, Gelman, \& Wellman, 2007).

In summary, children associate psychological traits with roles or domains, and internalize those roles or domains as self-aspects. Thus, children likely have a knowledge structure of the self developing in early childhood that is differentiated into self-aspects and the traits associated with these self-aspects.

\section{Applications}

\subsection{Motivation and Emotion Regulation}

As postulated by the multiple self-aspects framework, self-concept structure may underlie key processes in children's motivation. Although little work has examined the influence of psychological self-concept structure on children's motivation and emotion regulation, children as young as 6 years old are motivated to pursue future and ideal selves that are viewed as more overlapping or interconnected with their present selves (Oosterwegel \& Oppenheimer, 1993; Oyserman et al., 2012). Likewise, when a self-aspect appears to be unattainable, children become discouraged from pursuing traits related to that self-aspect. For instance, when preschoolers are outperformed by an other-gender peer rather than a same-gender peer, they perceive personal success as less attainable, because the ability to succeed at that task is ascribed to a gender role with which they do not identify. In contrast, if a role is incorporated into one's view of the self (i.e., it is a self-aspect), personal success is viewed as more attainable (Rhodes \& Brickman, 2008). Thus, when children pursue novel self-aspects or need greater motivation in a particular self-aspect, it is important for that self-aspect to be incorporated structurally into their current self-concept.

Self-concept structure could influence motivation further by moderating how children respond to feedback information. In predominantly positive and supportive environments, highly interconnected self-concept structure can be favorable, leading to higher affect regarding the overall self when positive feedback is received in one self-aspect (McConnell, Strain, Brown, \& Rydell, 2009). However, when conditions are less optimal or the feedback to be received is negative, criticism of one self-aspect may lead to negative affect about many self-aspects (McConnell et al., 2009). When adults with high overlap between self-aspects have their ability in one self-aspect threatened, they will disengage from future challenges that may confirm their failure (Brown \& McConnell, 2009). This directly parallels the feedback reactions of children with fixed mindsets, who view success as pass or fail (rather than a process requiring effort and growth; cf. Smiley \& Dweck, 1994). When children with fixed mindsets interpret their environment as disconfirming a positive trait (e.g., "smart"), they avoid the potential for further negative feedback (Smiley \& Dweck, 1994). Children with fixed mindsets may be experiencing high spillover between self-aspects because they have applied relatively inflexible ideas of the self across many domains, and now these ideas are being threatened. The impact of self-concept structure on this process hints that the effect of mindsets may be further moderated by how isolated or far-reaching a threat is in the self-concept.

Self-concept structure could also be useful in examining emotion regulation abilities. Adults with less overlapping self-concept structures were more able to distract themselves from self-concept threat (Renaud \& McConnell, 2002), much like Emani's father helped her to do in the introductory example. The more other self-aspects are available to think about that are not susceptible to negative spillover, the more successful individuals may be in regulating their emotional reactions to negative feedback. Children's ability to regulate emotions via distraction or self-affirmation (Meerum Terwogt \& Stegge, 1995) may be directly related to how well the structuring of their self-views allows for this type of refocusing and detachment from the current source of self-threat. Because of the many emotional and educational benefits of self-affirmation, understanding the role of self-concept in this process may be profitable. Expanding our knowledge of children's self-concept contents and structure can help us to understand motivation and emotion regulation better. 


\subsection{Development of Self-Aspects}

One of the benefits of understanding self-concept contents and structure together is the ability to discover how children adopt and organize self-aspects. As they develop, children create and differentiate between self-aspects for various academic and social domains (Marsh et al., 1991). Examining self-concept structure before and after children have the opportunity to adopt a novel self-aspect (e.g., before and after joining a sports team) could elucidate how children construct roles with respect to their pre-existing self-aspects. Researchers could also examine moderating factors, such as perceived competency in a given domain, internal motivations and sense of agency, and beliefs about values of different roles (Bandura, Barbaranelli, Caprara, \& Pastorelli, 2001), that may affect children's incorporation of a novel self-aspect into their self-concept.

Cognitive abilities, tendencies, and biases should also relate to the development of self-concept organization. With increased cognitive skill, children may become more likely to assign traits flexibly to different roles or domains. For instance, 5- to 10-year-olds who were taught to classify people according to multiple dimensions later showed better memory of gender counter-stereotypic traits (Bigler \& Liben, 1992). Similarly, greater cognitive flexibility could lead to more flexible assignment of traits to different self-aspects, resulting in more overlap between self-aspects. Furthermore, as children age, they develop more advanced ability in understanding others' mental states (i.e., Theory of Mind), which allows them to develop more sophisticated understanding of individual features and their influence on behavior (Chalik, Rivera, \& Rhodes, 2014).

Children's fixed or growth mindsets may influence how novel self-aspects are adopted into the self-concept structure. Those with fixed mindsets may be less likely to adopt novel self-aspects and be more fearful of the potential for new threats to their identity introduced via those self-aspects. In contrast, those with growth mindsets may be more likely to adopt novel self-aspects and integrate them into their sense of identity, as feedback is less likely to impact their views of self. Learning more about self-concept contents and structure could reveal how mindsets impact the construction and modification of self-knowledge networks.

Children's development and organization of self-views may also be impacted by positivity bias, which involves children's overly optimistic perceptions of their own and others' personality traits (Boseovski, 2010; Harter, 1999). Positivity bias may prompt children to generalize positive traits across self-aspects, leading to more interconnection in the self-concept structure. In contrast, negative traits may not be internalized, or else might be isolated to certain self-aspects. Additionally, although positivity bias is common, not all young children exhibit it (Boseovski, 2010). Examination of self-concept structure could elucidate whether unbiased children are less positive in their views of self, or whether they simply have more isolated positive self-views, either of which may lead to unhealthy outcomes like depression (cf. Abela \& Véronneau-McArdle, 2002). Patterns of trait adoption and valence may be important to consider for understanding healthy self-development.

Another bias, the "halo effect," may also influence self-concept development. Children exhibit a "halo effect" when the positivity from one trait indicates that other similarly positive traits are also present (Felson \& Bohrnstedt, 1979; Heyman, Gee, \& Giles, 2003; Stipek \& Tannatt, 1984). For instance, children will generalize that someone who is nice is also attractive and smart. Interestingly, children are less likely to generalize that someone who is attractive or smart is also nice (Felson \& Bohrnstedt, 1979). Clearly, children have theories of trait relations; positive traits, especially those related to social norms or morality (e.g., nice) are predictive of other positive traits. This corresponds with the developmental trend that children come to understand social traits earlier than internal psychological traits (Benenson \& Dweck, 1986; Yuill, 1992). Examining children's individual trait theories about the interconnections of their own traits may reveal the origin of biases for interpreting others' traits in certain ways (Critcher, Dunning, \& Rom, 2015). Investigating how patterns of traits are incorporated into the self-concept structure could reveal how these biases (or trait theories) impact the construction of self-concept.

\subsection{Enhancements to Existing Model}

We have highlighted several key components of an enhanced model for early self-concept development, inspired by the multiple self-aspects framework (McConnell, 2011). We are emphasizing additional attention to types of self-aspects (including social categories/identities, social relationships, and activity domains), as these may hold different weight and follow different developmental trajectories in the self-concept. It is also critical to consider the role of different types of traits; certain traits (i.e., social norm or moral traits) carry more weight than other types of traits for young children, and emerge earlier. Thus, an enhanced model of self-concept development would account for types of self-aspects and of self-concept contents.

Although we have focused on psychological and emotional trait contents in the present article, we do recognize that these must be considered alongside other contents, such as the better-studied self-worth, evaluative affect, and 
self-efficacy attributes of self-concept.

\section{Conclusion}

Richer research into self-concept development promises elaboration of current knowledge and models of the self. We have proposed an application of the multiple self-aspects framework to childhood self-concept and have introduced some key considerations for this model in early development. Furthermore, we have highlighted several future directions for examining the relation of self-concept to processes including motivation, emotion regulation, and cognitive abilities and biases.

\section{References}

Abela, J. R. Z., \& Véronneau-McArdle, M. (2002). The relationship between self-complexity and depressive symptoms in third and seventh grade children: A short-term longitudinal study. Journal of Abnormal Child Psychology, 30(2), 155-166. Retrieved from http://www.ncbi.nlm.nih.gov/pubmed/12002396

Ambady, N., Shih, M., Kim, A., \& Pittinsky, T. L. (2001). Stereotype susceptibility in children: Effects of identity activation on quantitative performance. Psychological Science, 12(5), 385-390. https://doi.org/10.1111/1467-9280.00371

Bandura, A., Barbaranelli, C., Caprara, G. V., \& Pastorelli, C. (2001). Self-efficacy beliefs as shapers of children's aspirations and career trajectories. Child Development, 72(1), 187-206. https://doi.org/10.1111/1467-8624.00273

Benenson, J. F., \& Dweck, C. S. (1986). The development of trait explanations and self-evaluations in the academic and social domains. Child Development, 57, 1179-1187. https://doi.org/10.2307/1130441

Bennett, M., \& Sani, F. (2008). Children's subjective identification with social groups: A group-reference effect approach. British Journal of Developmental Psychology, 26, 381-388. https://doi.org/10.1348/026151007x246268

Bigler, R. S., \& Liben, L. S. (1992). Cognitive mechanisms in children's gender stereotyping: Theoretical and educational implications of a cognitive-based intervention. Child Development, 63, 1351-1363. https://doi.org/10.2307/1131561

Bigler, R. S., \& Liben, L. S. (2007). Developmental Intergroup Theory: Explaining and reducing children's social stereotyping and prejudice. Current Directions in Psychological Science, 16(3), 162-166. https://doi.org/10.1111/j.1467-8721.2007.00496.x

Boseovski, J. J. (2010). Evidence for "rose-colored glasses": An examination of the positivity bias in young $\begin{array}{lllll}\text { children's personality. Child Development Perspectives, } & 4(3), & \text { 212-218. }\end{array}$ https://doi.org/10.1111/j.1750-8606.2010.00149.x

Brown, G. L., Mangelsdorf, S. C., Agathen, J. M., \& Ho, M. (2008). Young children's psychological selves: Convergence with maternal reports of child personality. Social Development, 17(1), 161-182. https://doi.org/10.1111/j.1467-9507.2007.00421.x

Brown, C., \& McConnell, A. (2009). Effort or escape: Self-concept structure determines self-regulatory behavior. Self and Identity, 8(4), 365-377. https://doi.org/10.1080/15298860802377818

Bryan, C. J., Master, A., \& Walton, G. M. (2014). "Helping” versus "being a helper": Invoking the self to increase helping in young children. Child Development, 85(5), 1836-1842. https://doi.org/10.1111/cdev.12244

Chalik, L., Rivera, C., \& Rhodes, M. (2014). Children's use of categories and mental states to predict social behavior. Developmental Psychology, 50(10), 2360-2367. http://dx.doi.org/10.1037/a0037729

Critcher, C. R., \& Dunning, D. (2014). Self-affirmations provide a broader perspective on self-threat. Personality and Social Psychology Bulletin, 4l(1), 3-18. https://doi.org/10.1177/0146167214554956

Critcher, C. R., Dunning, D., \& Rom, S. C. (2015). Causal trait theories: A new form of person knowledge that explains egocentric pattern projection. Journal of Personality and Social Psychology, 108(3), 400-416. http://dx.doi.org/10.1037/pspa0000019

Cvencek, D., Greenwald, A. G., \& Meltzoff, A. N. (2016). Implicit measures for preschool children confirm self-esteem's role in maintaining a balanced identity. Journal of Experimental Social Psychology, 62, 50-57. https://doi.org/10.1016/j.jesp.2015.09.015

Diesendruck, G., \& haLevi, H. (2006). The role of language, appearance, and culture in children's social $\begin{array}{llll}\text { category-based } \quad \text { induction. } & \text { Child } & \text { Development, } & \text { 77(3), }\end{array}$ 
https://doi.org/10.1111/j.1467-8624.2006.00889.x

Eder, R. A. (1990). Uncovering young children's psychological selves: Individual and developmental differences. Child Development, 61, 849-863. https://doi.org/10.2307/1130969

Felson, R. B., \& Bohrnstedt, G. W. (1979). Relationship between children's perceptions of ability and perceptions of physical attractiveness. Social Psychology Quarterly, 42(4), 386-392. https://doi.org/10.2307/3033808

Gelman, S. A. (2003). The essential child: Origins of essentialism in everyday thought. New York, NY: Oxford University Press.

Gelman, S. A., \& Heyman, G. D. (1999). Carrot-eaters and creature-believers: The effects of lexicalization on children's inferences about social categories. Psychological Science, 10, 489-493. doi:10.1111/1467-9280.00194

Greenwald, A. G., Banaji, M. R., Rudman, L. A., Farnham, S. D., Nosek, B. A., \& Mellott, D. S. (2002). A unified theory of implicit attitudes, stereotypes, self-esteem, and self-concept. Psychological Review, 109(1), 3-25. https://doi.org/10.1037//0033-295x.109.1.3

Harter, S. (1983). Developmental perspectives on the self-system. In E. M. Hetherington (Ed.), P. H. Mussen (Series Ed.), Handbook of child psychology: Vol. 4. Socialization, personality, social development (pp. 275-385). New York: Wiley.

Harter, S. (1985). Self-Perception Profile for Children: Revision of the Perceived Competence Scale for Children. Denver, CO: University of Denver.

Harter, S. (1999). The construction of the self. New York: Guilford Press.

Heyman, G. D., Gee, C. L., \& Giles, J. W. (2003). Preschool children's reasoning about ability. Child Development, 74(2), 516-534. https://doi.org/10.1111/1467-8624.7402013

Kalish, C. W. \& Lawson, C. A. (2008). Development of social category representations: Early appreciation of roles and deontic relations. Child Development, 79(3), 577-593. https://doi.org/10.1111/j.1467-8624.2008.01144.x

Linville, P. (1987). Self-complexity as a cognitive buffer against stress-related illness and depression. Journal of Personality and Social Psychology, 52(4), 663-676. https://doi.org/10.1037//0022-3514.52.4.663

Liu, D., Gelman, S. A., \& Wellman, H. M. (2007). Components of young children's trait understanding: Behavior-to-trait inferences and trait-to-behavior predictions. Child Development, 78(5), 1543-1558. https://doi.org/10.1111/j.1467-8624.2007.01082.x

Marsh, H. W., Craven, R. G., \& Debus, R. (1991). Self-concepts of young children 5 to 8 years of age: Measurement and multidimensional structure. Journal of Educational Psychology, 83(3), 377-392. https://doi.org/10.1037//0022-0663.83.3.377

McConnell, A. R. (2011). The multiple self-aspects framework: Self-concept representation and its implications. Personality and Social Psychology Review, 15(3), 3-27. https://doi.org/10.1177/1088868310371101

McConnell, A. R., Strain, L. M., Brown, C. M., \& Rydell, R. J. (2009). The simple life: On the benefits of low self-complexity. Personality and Social Psychology Bulletin, 35(7), 823-835. https://doi.org/10.1177/0146167209334785

Meerum Terwogt, M., \& Stegge, H. (1995) Children's understanding of the strategic control of negative emotions. In J. A. Russell, J. N. Fernandez-Dols, A. S. Manstead, \& C. Wellenkamp (Eds.), Everyday conceptions of emotion (pp. 373-690). Dordrecht, the Netherlands: Springer.

Murphy, G. L., \& Medin, D. L. (1985). The role of theories in conceptual coherence. Psychological Review, 92, 289-316. https://doi.org/10.1037//0033-295x.92.3.289

Nelson, K., \& Fivush, R. (2004). The emergence of autobiographical memory: A social cultural developmental theory. Psychological Review, 111(2), 486-511. https://doi.org/10.1037/0033-295X.111.2.486

Oosterwegel, A., \& Oppenheimer, L. (1993). The self-system: Developmental changes between and within self-concepts. Hillsdale, NJ: Lawrence Erlbaum Associates.

Oyserman, D., Elmore, K., \& Smith, G. (2012). Self, self-concept, and identity. In M. R. Leary \& J. P. Tangney (Eds.), Handbook of self and identity (pp. 69-104). New York: Guilford.

Pauker, K., Ambady, N., \& Apfelbaum, E. P. (2010). Race salience and essentialist thinking in racial stereotype development. Child Development, 81(6), 1799-1813. https://doi.org/10.1111/j.1467-8624.2010.01511.x 
Reis, H. T., \& Wright, S. (1982). Knowledge of sex-role stereotypes in children aged 3 to 5. Sex Roles, 8(10), 1049-1056. https://doi.org/10.1007/bf00290999

Renaud, J. M., \& McConnell, A. R. (2002). Organization of the self-concept and the suppression of self-relevant thoughts. Journal of Experimental Social Psychology, 38(1), 79-86. https://doi.org/10.1006/jesp.2001.1485

Rhodes, M., \& Brickman, D. (2008). Preschoolers' responses to social comparisons involving relative failure. Psychological Science, 19(10), 968-972. https://doi.org/10.1111/j.1467-9280.2008.02184.x

Sani, F., \& Bennett, M. (2009). Children's inclusion of the group in the self: Evidence from a self-ingroup confusion paradigm. Developmental Psychology, 45(2), 503-510. https://doi.org/10.1037/a0014167

Shavelson, R. J., Hubner, J. J., \& Stanton, G. C.. (1976). Self-concept: Validation of construct interpretations. Review of Educational Research, 46(3), 407-441. https://doi.org/10.2307/1170010

Smiley, P. A., \& Dweck, C. S. (1994). Individual differences in achievement goals among young children. Child Development, 65, 1723-1743. https://doi.org/10.2307/1131290

Spokes, A. C., \& Spelke, E. S. (2016). Children's expectations and understanding of kinship as a social category. Frontiers in Psychology, 7:440. https://doi.org/10.3389/fpsyg.2016.00440

Stipek, D. J., \& Tannatt, L. (1984). Children's judgments of their own and their peers' academic competence. Journal of Educational Psychology, 76, 75-84. https://doi.org/10.1037/0022-0663.76.1.75

Yuill, N. (1992). Children's production and comprehension of trait terms. British Journal of Developmental Psychology, 10, 131-142. https://doi.org/10.1111/j.2044-835x.1992.tb00567.x

\section{Copyrights}

Copyright for this article is retained by the author(s), with first publication rights granted to the journal.

This is an open-access article distributed under the terms and conditions of the Creative Commons Attribution license (http://creativecommons.org/licenses/by/4.0/). 